\title{
The innovative potential and problems of the modern IT projects
}

\author{
Monika Woźniak \\ University of Gdańsk, Department, Faculty of Management, Department of Business \\ Informatics, Poland \\ monika@univ.gda.pl
}

\begin{abstract}
Study of the latest research reports shows dispute on the innovative potential in the IT industry. Although spending Polish companies on IT are growing steadily, in parallel there is a large proportion of dissatisfied customers and failed projects. At the same time, IT has grown enough in structure and operation of companies that innovation should not be discussed without IT. These issues have led the author to undertake research into their causes. The results obtained allowed to establish the modern requirements and expectations of the IT industry and indication of current, critical success factors of IT projects. On the basis, the directions of changes to boost the degree of success of IT projects are indicated in the article, thus giving a chance to restore the role of the IT industry as a leader of innovation for companies.
\end{abstract}

Keywords: IT innovation, the effectiveness of IT projects, the evolution of roles in IT, IT leadership profile, role and place of customer in IT

\section{$1 \quad$ Introduction}

Today, innovation and entrepreneurship are closely related [2]. The organization's environment is characterized by increasingly dynamic changes in recent years. This trend was reflected in the business sector in the form of pressure to produce innovative ideas, recruiting more and more and better professionals, over-extension department R \& D (Research and Development), increased spending on innovation [3].

Often, however, despite these procedures, the company cannot achieve the position of an innovative enterprise in the eyes of customers and the market. This is due to misunderstanding of the changes taking place in the phenomenon of innovation. Innovation has evolved from a focus on new technologies, through new products, to turn towards the real value for customers [14]. The derivative of these changes in the interpretation of innovation is currently defined innovation in terms of customers. Only such an approach can provide companies a success.

The special nature of innovation is related to IT. The last few years points to the inherent link between innovation activity in business with the development of information technology [11]. IT products have become for many companies foundation on innovation processes, models of collaboration, customer service, information, etc. The 
key role in this field plays IT staff. They are expected to propose and fit the latest IT solutions in demand of company, in order to make it innovative. In research reports in recent years, however, appears increasingly questioning the potential of innovative IT industry [7], [19]. What are the reasons? Why modern IT products, individually ordered not translate into innovation in the company? What is the real conflict between IT staff and end user of the products? Why new IT design methodologies are not reflected in the number of projects completed with full success? This article is an attempt to answer these questions and determine the path of change.

\section{Conditions for analysis of current reports}

The era of entrepreneurship closely related to innovation gives the dynamics of the IT market. Key factors in the development of the IT market in Poland in 2011 is nearly $20 \%$ increase in awareness of the needs of IT and 32\% increase in the propensity of firms to invest in IT [16]. Analysis of the results of numerous reports (The Standish Group Report 2011, PMR Report 2011, Gartner Report 2011) indicates a continuous increase in spending money on IT in Polish companies. The rate of this increase was a big surprise because it has exceeded projections by 2.5 percentage points. This increase was mainly developed by the software market, not the hardware market, as it did in previous years. Companies increasingly recognize the need for customized software as a source of innovation and not only expansion of technical-hardware facilities. The result has been $11 \%$ increase in investment in this area.

In opposition to these growth trends, presents the results of research on the success of IT projects. More than half of IT projects fail. Despite the growing trend of projects successfully completed, the percentage of IT projects completed with full success still is not satisfactory (only 35\%) [7]. Among the reasons for this is given excess one of four basic parameters of the project: time, budget, scope or quality. These factors are only general guidelines. Detailed reasons are possible for disclosure through in-depth, qualitative research methods (interview, observation).

\section{The research problem and research methodology}

Analysis of the results of mentioned reports indicates the need for the emergence of a new trend going from building up in the direction of consulting. This phenomenon will result in the need for both the evolution of roles in IT, as well as the revaluation of the place and role of customer in the IT projects. Therefore, the investigations undertaken were divided into two parts connected with them in scheduled thematic areas:

- IT projects and staff,

- client and its place in IT projects. 
For each area of research used other methodologies. The methodology was selected in accordance with the principle of maximizing the quality and quantity of obtained information, necessary to obtain a complete view of the investigated phenomenon [8].

The study included Polish IT company, providing custom software services, which in the first half of 2011 was initiated more than two IT projects.

For the first research area - projects and IT staff, focus group interview was used. Important for research in this area were qualitative information, providing comprehensive answers to questions like "Why" [18]. In addition, more importantly, applying focused interview, achieved the effect a broader perspective [13]. The participants of the interviews in each study were both managers at various levels, as well as a number of IT staff. This created an opportunity to confront the questions posed in the research and get a complete view.

The second area of research, client and its place in IT projects is made by observation [10]. It had been during the implementation of IT projects in the companies surveyed. This has provided an overview of the actual place and role of the client in a variety of methodologies for IT projects. This allowed the identification of critical success factors on IT project and identify necessary changes in this regard. The study consists of the following layers shown in Figure 1.
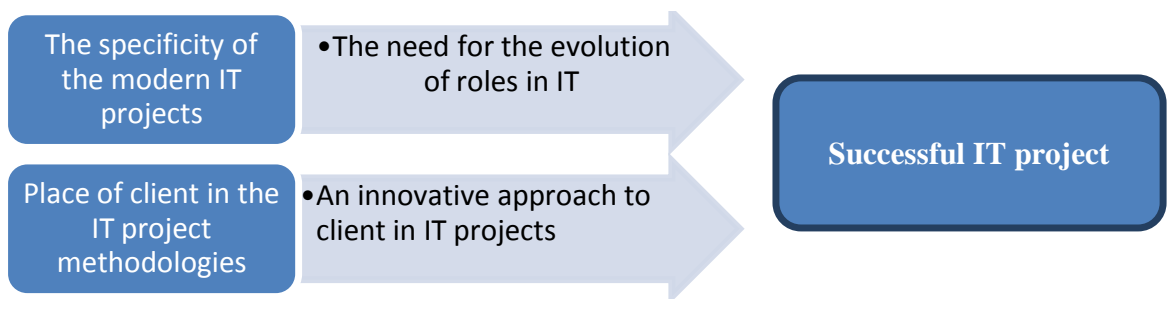

Fig. 1. Layers of research

\section{The specificity of the modern IT projects}

In the face of modern growing demands and requirements of end-user for IT and rapidly changing market conditions, the approach to IT projects must constantly evolve. Today's business world in the era of innovation not only expects from IT technical innovations, but systems tailored to current needs [17]. Thus, in the reports is a growing rate of investment in software.

Despite the dynamic development of the IT industry growing number of demanding and dissatisfied customers. This aspect is quite often discussed in interviews, combined with reports indicating that more than half of IT projects fail.

All the companies surveyed agreed on the specifics of today's emerging IT ventures [15]. As the most important aspects are considered:

- large extent and uniqueness,

- high degree of difficulty,

- high degree of risk, 
- inclusion in the rapidly changing market conditions and environment, which translates into the need for flexibility in the implementation of IT projects.

Today customers expect customization of IT products to the dynamically changing characteristics of their needs. Under these conditions, companies recognize the need to move away from templates and schematic in IT projects. Large individual scope, uniqueness and variability exclude repeatability of the IT projects.

The surveyed companies acknowledged explicitly that:

- use of proven methodologies for IT project management,

- continuous improvement of mechanisms and design technology of IT,

- technical training of staff,

not produce the expected results in the increased number of successful projects.

Identified the real causes of IT project failures. These include lack of: awareness of the role of the client, the main management support and clearly defined requirements. Other factors were mentioned, but the three were found to be most significant. At the same time observations showed that awareness of the role of the customer and the ability to create his proper place in the IT project is foreground, a critical success factor. Many times it would prejudge the success of IT projects.

Summing up the above information obtained from research, you should understand that the key to success in IT innovation, it is no longer improving technologies, tools and methods, but a switch to the customer, enabling it to cooperate. This approach, however, will require a whole series of changes in the mentality of IT teams and their methods of work.

The following areas should be taken into consideration while indicating the directions of change, to boost the success of IT projects as sources of innovation:

- modern requirements and expectations placed on IT,

- evolution of roles in IT,

- today's IT leadership role,

- customer's place and role in IT projects.

\section{The need for the evolution of roles in IT}

Research indicates the need for fundamental change in the IT industry. The roles and attitudes of IT employees and the quality of their relationships with the business, and existing client are the factors that should undergo the evolution. Forrester analysts also predict that will change work patterns in IT-related occupations will be changed, and many IT roles will tend in the direction of management [4].

The approach of the above mentioned changes indicate the need of transformation at all levels of IT staff:

- IT staff,

- IT leaders. 
In particular, the requirements and expectations disclosed in the study concerning IT staff are often in opposition. For example, the requirement of maximum concentration on the task while expectation for openness and communication.

In response to the conflict between the requirements and expectations, growing challenges and pressures in relation to IT workers would take a two-fold action:

- profiled system IT staff training,

- selection or creation of an appropriate IT leader.

Becomes necessary to develop a new strategy for human resources management in IT. Should be extended set roles of IT about the aspects allowing overcoming the serious problem of the relationship on the line of the IT department and the environment. This can be achieved through training shaped for the development of relations with the environment, taking into account the specificity of trained IT profile. Profiled training system should be considered in the context of the size of the company and its needs with the number of clients and spread of implemented projects. Usually size of the company translates into the structure and develop the IT department and hence the diversity of requirements for their regular employees and IT leaders at various levels.

In small and some medium-sized businesses division of tasks between the leader and the IT staff is not very sharp [21]. Since these employees are expected to adopt high flexibility and such training system that will enable them it.

In large and some medium-sized companies investing in human resource development should be based on the use of different strategies of employee training. Particular care must be taken in the complex structure of IT leaders. This is because they, as a result of the evolution of roles in IT, will be responsible for communication and relationships with the environment [20].

\section{Today's IT leader}

Changes in the mentality of IT work will not be possible to occur without creating adequate IT leader. The current profile of the IT leader in most of the surveyed companies oscillates around computer scientists and engineers. Their attention is not focused on information and communication with the environment, but on the technology and IT processes. In fact, act as a director for more than a leader in IT technology[5].

Evolution of IT leaders should be heading in the direction of the transfer preferences and knowledge of the characteristics typical for computer scientists - engineers and analysts on the characteristics, knowledge and skills corresponding to modern management [9].

Determined above specificity of modern IT projects implies the need to create a new paradigm of IT leadership. In this pattern should be included:

- possession of current technology - technical knowledge,

- knowledge about management and business processes,

- interpersonal skills and conduct effective interactions with customers, 
- flexible and efficient IT team management,

- need to contribute the company's communities,

- active participation in the IT leaders environment.

The profile of today's IT leader must be so shaped that its ability allow the leveling of the critical factors of failure of IT projects and implementation of innovative projects. According to studies, the most important are:

- establish good relations with any type of customer,

- knowledge and ability to apply the methods of engaging the customer,

- awareness and ability to cope with risks and threats associated with the project,

- awareness and use of the implication between the type of customer and the IT project methodology.

- effective management of the potential of your team (to maximize the effects of work both in the implementation of assigned tasks, as well as in difficult situations).

In contacts company-customer IT leader is the main figure. As stated, the lack of awareness of the customer's role is a critical factor in the failure of IT projects. IT leader is in turn a part of a company that is closest to the customer in IT projects. Therefore, its role and functions are nerve center of IT projects in terms of their effectiveness. A special note should be subject its interaction with the customer.

\section{$7 \quad$ An innovative approach to customer in IT projects}

In the study particular attention was given at the role of customer in IT projects due to the following conditions: the existence of a large range of industry-accepted methods for managing IT projects [12], still unsatisfactory percentage of successful projects and a continuous indication at client as a primary factor in IT project failures. This led the author to attempt to verify the customer's actual place in IT projects.

Popularization and rapid development of IT project management methodology, proven to be "dead end" in terms of expectation of significant improvement in the degree of success of IT projects. Our observations reveal a hidden cause of this phenomenon. It is too mechanical and stereotyped, and often rudimentary setting the place and role of the customer. Due to the unique, high degree of difficulty, a large range and variability of ongoing IT projects becomes necessary to change the approach to the client [6].

In all observations of IT projects, irrespective of the type of methodology, there were the same aspects of a client's factor. The most commonly reported include: problems with client involvement, lack of input information from the customer, incomplete requirements, changing customer requirements, unrealistic expectations.

The studies performed shown that the same kind used of IT project methodology is not as important to the success of IT project. Critical factors were:

- ability to communicate with the client,

- ability to assess the type of customer, 
- planned and effective interaction of the IT team - client,

- knowledge and assessment how to match the characteristics of the client to the methodology used to project IT,

- ability to develop ways to compensate the lack of a satisfactory correlation between the customer and the IT project methodology (e.g., customer engagement techniques).

In the area of communication a common barrier is industry-specific language on both the client and the IT team. Therefore, the more important is the evolution of roles in IT and introduction of IT leadership as a link between company - customer. Looking through the prism of the effectiveness of customer relationship, the leader needs to have at primarily interpersonal skills and communication skills. This is the basis without which the other necessary elements will not be able to reveal and effectively be used [1].

It is also necessary to introduce a new practice - reliable assessment of the client. For the purpose of the conducted research author applied the concept of customer's level of maturity. At the concept of maturity will consist of two aspects of synergy the awareness and willingness to cooperate (engage).

A huge advantage of the company will be its skills in assessment the level of client's maturity and determination the combination of features that make up for it. Only companies having and practicing this skill, combining it with the knowledge of requirements of adopted IT project methodology, will be able to plan effective interaction with the customer. A reasonable would then be expectation to increase the efficiency of projects IT.

Of the great importance is the knowledge about the optimum combination of maturity aspects for specific of given methodology. This knowledge, combined with the assessment of the client, create a view of the degree of matching the customer to used IT project methodology. This is another item that will work to generate success in the modern IT projects.

Awareness of the lack of fit between the client and the applied IT project methodology should involve the identification and assessment of the type and scope of the present deviations. The next step is to take the appropriate action to as far as possible the approximation of a different customer profile to the preferences of a particular methodology. The company should develop its path client's "adaptation" to the used IT project methodologies. This process should be based on specific methods and techniques that increase the involvement or awareness, depending on which aspects of maturity is a critical element in the effectiveness of the chosen methodology. This is summary action an innovative approach to client in IT projects.

In summary - the success of the modern IT projects is not in the creation of further methodologies and supporting their next technical achievements, but in paying attention to the role and place of the client in IT projects. IT companies must begin to perceive a client not only as to someone who creates a product, but as an integral part of a dynamic process affecting its quality and evolution. 


\section{Conclusion}

Together with changing market conditions for the IT industry, approach to IT projects must constantly evolve. The challenge now in this area is the need to reflect on the way to meet the specifics of the modern IT projects. Translating type and direction of change in IT, from formal and technical to society is now becoming a necessity. The answer to the growing challenges and expectations of the business to IT will not take place a corresponding change in the IT teams, mainly related to the evolution of roles and mindset change. Equally important is the transformation of customers approach awareness of its role and give its rightful place in the processes of IT.

It is important that on the basis of well-targeted research to capture the conditions and trends of current changes, identify weaknesses and on that basis draw the critical factors and trends to boost the success of IT projects.

The key therefore to overcome the currently prevailing criticism of the innovative potential of IT is to develop a new culture of cooperation in the line IT - the customer. And more specifically the promotion of cooperation between the creators of IT product and the customer. Promoting a new culture can help to realize the full potential of both IT workers and clients, and their mutual interactions. This approach is the opportunity to re-make from the IT industry the leader in innovation for companies.

\section{References}

1. Baney, J.: Guide to Interpersonal Communication (Guide to Business Communication Series), Prentice Hall, 2009.

2. Chesbrough, H.: Open Innovation. The New Imperative for Creating and Profiting from Technology. Harvard Business School Press, Boston, 2003.

3. Drucker, P.: Innovation and Entrepreneurship. Harper Business, 2006.

4. Forrester Research, webinarium, http://www.columbusglobal.com/, january 2012.

5. Foundation IT Leader Club Poland, http://www.itleader.pl/Fundacja.html, 2011.

6. Garai, L.: Identity Economics - An Alternative Economic Psychology, http://www.usc.edu/libraries/archives, 2009.

7. Gartner Report 2011.

8. Gauch, H.: Scientific Method in Practice. Cambridge University Press, 2002.

9. Harvey Nash: IT Leadership Report, 2011.

10. Hennink, M., Hutter, I., Bailey A.: Qualitative Research Methods. Sage Publications Ltd, 2010.Hoque, F., Bruckner, J.: The Power of Convergence: Linking Business Strategies and Technology Decisions to Create Sustainable Success, AMACOM, 2011.

12. Koszlajda, A.: Zarządzanie projektami IT. Przewodnik po metodykach (IT Project Management. Guide to the methodologies), Helion, 2010.

13. Krueger, R., Casey, M.: Focus Groups: A Practical Guide for Applied Research. Sage Publications, 2000.

14. Laperche, B., Uzunidis, D., Tunzelmann, N.: Genesis Of Innovation: Systemic Linkages Between Knowledge and the Market (New Horizons in the Economics of Innovation). Edward Elgar Pub, 2008.

15. Phillips J.: IT Project Management. On Track from Start to Finish. The McGraw-Hill Companies, 2011. 
16. Report PMR, Rynek IT w Polsce 2011. Prognozy rozwoju na lata 2011-2015. (IT market in Poland 2011. Development forecasts for 2011-2015).

17. Report Queensland Audit Office, CIO Magazine of Directors IT, Australia, 2011.

18. Silverman, D.: Interpreting Qualitative Data: Methods for Analyzing Talk, Text and Interaction. Sage Publications Ltd, 2006.

19. The Standish Group Report, 2011.

20. Withers, M., Williamson, M., Reddington, M.: Transforming HR, Second Edition: Creating value through people. Taylor \& Francis, 2009.

21. Żebrowski, M., Waćkowski, K.: Strategiczne zarządzanie innowacjami. Strategiemałychiśrednichprzedsiębiorstw IT. (Strategic innovation management. Strategies for small and medium IT enterprises.), Difin, 2011. 